which has the disadvantage that curves of growth tend always to be confused by curves of distribution).

It is not usual for practitioners of a science to write of its history, but if it comes off, as it does here, the result is a triumph. Tanner could hardly do otherwise than begin with the voluminous and in the main tiresome works by or attributed to Aristotle: instead of calling attention to his more egregious and least easily explicable blunders, such as the belief that human semen is infertile until the age of 21, Tanner makes the best of Aristotle by finding grounds for the neat and convincing inference that "in 350 BC children were maturing at approximately the same rate as now".

Among Tanner's most interesting passages are those that deal with the hebdomadal tradition: the number-magic that found expression in the belief that the body is divided into seven parts and the life of man into seven stages each seven yearś long.

The mystique attached to the seven-fold system makes reliance on the truth of any actual age impossible however; both at the time and for centuries later there is a tendency for all ages to be rounded to the nearest hebdomadal number.

Tanner is a learned and widely read man, and his book is full of fascinating historical and sociological insights:

the growth of children of the manual labouring classes in England in the 1830s, and even the 1870s, was still more depressed than that of the poorer groups in some of the underdeveloped countries nowadays .... we should not be too surprised. Indeed children of slaves in the plantations of the southern states of America at this time . . . were taller (by some 2 to $5 \mathrm{~cm}$ ) than contemporary children of manual labourers in England (although nowadays the heights of children of European and of African descent living under similar economic circumstances are almost identical).

Tanner devotes some amusing paragraphs to passages from J.J. Virey ("that would have done credit to Baden Powell"') professing to demonstrate the debilitating effects of masturbation. J.J. Virey (1775-1846) was a pharmacist who contributed to the Dictionnaire des Sciences Médicale.

Although the book is mainly about human growth, Tanner casts a wider net and manages to make mention of D'Arcy Thompson, who had little to say about human growth. As an admirer of D'Arcy's, I can vouch that Tanner's placing and appraisal of him are exactly right - "a late flower of the Renaissance" who wrote superlative prose.

This is an excellent book which may be read with advantage by all biologists interested in the history of ideas - and should certainly be read by sociologists and social historians as well.

Sir Peter Medawar is Head of the Transplantation Biology Section at the Medical Research Council's Clinical Research Centre, Harrow, Middlesex.

\title{
Education in science, science in education
}

\section{Nevill Mott}

Science in Schools: Which Way Now? By Richard Ingle and Arthur Jennings. Pp.185. ISBN pbk 0-85473-100-8. (University of London Institute of Education/NFER-Nelson: 1981.) £5.30.

THE authors of this book give an account of what has been happening in science education in the UK and of what, in their opinion, ought to happen now. One of them graduated in physical sciences, the other in biology; both had considerable experience of school teaching before moving into the field of teacher training and educational research. The emphasis of their book is on "science for all" and it gives as clear a discussion as any I have seen of the objectives to be achieved by giving all children, up to the age of 16 , considerable time for science. What the authors discuss rather little, in that they do not present it as a separate problem, are the needs of that minority who after further education are going to make use of their science, as engineers, technicians, research scientists and doctors.

The rise of general science in the interests of science for all, and its subsequent decline up to the time of the change to comprehensive education, is described here, as it is perhaps more fully in the chapter "The General Science Movement"' in E.W. Jenkins's book From Armstrong to Nuffield (John Murray, 1979). In the years between the two wars, Ingle and Jennings say that the move towards general science was based on the notion that science should be for everyone, not just for the embryonic professional scientists (which presumably includes engineers, doctors and others), and that it should form an essential part of the general education of all young people. But in practice, they add, general science was found to be "a scrappy mixture of physics, chemistry and biology', Certainly, in the immediate pre- and postwar periods it enjoyed little prestige as a university subject, in comparison with the specialist honours degrees. Moreover in the post-war period, policy-makers, conscious of the role of science in the war and of the perceived need for qualified scientists and engineers (QSEs) in industry, had little use for general science. Two authorities, quoted by Jenkins (p.99) wrote that

An improvement in . . . school science teaching is a requirement for the continued existence of this country as a leading scientific and industrial nation. As a first step in this direction general science should be abandoned.

Ingle and Jennings report that in the $1950 \mathrm{~s}$, in independent and grammar schools, general science was declining fast and two or three specialist $\mathrm{O}$-levels were the norm. However, in the secondary modern schools, they say, teacher training colleges serving them were sufficiently independent from universities to help teachers make the science more child-centred and less academic than in grammar schools. Unfortunately these teachers were rarely encouraged to publish their methods, "so that their experience and wisdom died with them".

A second chapter deals with "the curriculum development era", starting in 1960 , and particularly the Nuffield Science Teaching Project, beginning in 1961-1962. This aimed to produce material in the three separate sciences, initially in the age group 11-16, for children in the selective grammar schools, and equally suitable for both future science specialists and others. In all three projects it was the aim that children would learn science largely through experimental enquiry, with the guidance and support of the teacher. The reception of Nuffield in the schools is described, as is its influence even in schools where the whole package was not accepted. Two criticisms of the original Nuffield scheme have been that the work was very demanding, even for the more able pupils, and that neither the O-level nor A-level schemes went far in illustrating the social relevance of science. Later projects for the less able child are described, including Nuffield Science 13-16 (now being published), the Association for Science Education's (ASE) project for "Less Academically Motivated Pupils"'(LAMP), and also the much more demanding Schools Council's Integrated Science Project (SCISP), which with a time-table allocation equivalent to that for two $\mathrm{O}$-levels brings together the three sciences with time for ample attention to be paid to their social aspects. Also described is the Schools Council's Project Technology, which had the aim of helping pupils to understand the importance of engineering in our way of life. In spite of the expenditure of $£ 300,000$, this project, they say, has had little impact; perhaps this is because science teachers teach best what they know best, and very few science teachers have been trained as engineers. In this context, the authors include an apposite quotation from B. Prescott:

Perhaps one of the greatest weaknesses of science teaching is that it is science teachers who do it - science teachers who have been initiated into the profession by science teachers and they teach courses written by scientists and science teachers.

But if this is a weakness, how is it to be corrected?

In chapters on aims and ideals ir. science education, and on hopes for the future, Ingle and Jennings identify themselves with the swing back towards general science and science for all, and away from the objective of producing QSEs, a movement which has undoubtedly taken place in the last decade. Reasons for this 


\section{IMAGE \\ UNAVAILABLE FOR COPYRIGHT REASONS}

Physics for sixth-formers - in the 1980s will they receive the grounding they need?

are perhaps the introduction of comprehensive schools, the unfavourable image that science and technology has sometimes presented and a widespread reaction against the so-called elitism of conventional scientific education. An extreme example of this reaction was the issue by the ASE of its discussion document "Alternatives for Science Education" (1979) which two years ago sent a shock wave of dissent through more conservative circles.

In this document it was claimed that science education as it is now is elitist, designed for the minority intending to make a career in science and against the interests of the majority. Alternatives were suggested, some of which seemed to propose teaching more about the role of science in the modern world than the practice of science itself. The ASE's most recent document, "Education through Science", issued in August 1981, puts forward a more moderate policy for the future which does not differ much from the proposals in the book under review, and which indeed carries widespread support. It is proposed that in all schools for children between 11 and 16, one-sixth of school time should be spent on science this would correspond to the time spent on two O-levels - and that integrated courses including physics, chemistry and biology, tit-bits of other sciences and coverage of social implications would be devised. This, it is claimed, would avoid irrevocable choices at 13, which so often cut children and particularly girls off from careers in science and its applications. Also it would avoid the lack of balance between science and the humanities which the study of three separate science subjects is said to involve.

Thus science education, as mapped out in this book, should be intended for all children. Rather than summarizing the aims set forth by the authors, the flavour of their argument may be given by the following quotation from a CSE project report which they include in the book:

My project worked very well and I'm pleased because (i) I got alcohol from paper which I thorught was never possible, (ii) because I used some new aquipment which I've never herd of let alone worked with. Another thing I was pleased about was there was lots of experiments and if there was anything I wanted to know there was book's at my finger tips so there wern't any time lost. If I had a lot more time what I would like to make is a lot more alcohol and do lots of flame tests because I only made about $1 \mathrm{~cm}^{3}$ of pure alcohol. So I could not do much, I would allso like to find how much yeast is necessary to ferment it propley yet let the alcohol burn propley. I would also like to know if it was the yeast that stopped it burning. I would also like to learn how to control the heat when distilling because that a mistake I made.

Curiosity, ability to think and to form ideas of what science and technology are about are to be emphasized. The authors recognize that "there are many young people who will leave school to seek employment in some field of science and technology, and that these will need a more extensive knowledge of science"'. Reference is made to "the more demanding courses that may be necessary to engage their minds and prepare them for sixth form studies". The italics are mine. Little discussion is devoted to the vexed question of setting or streaming for these more demanding classes. The authors give the impression that, although they realize that setting in science subjects (or avoidance of science by the less talented) is almost universal, at any rate from 14 to 16 , they hope that mixed ability teaching will spread. But this book does at least recognize the needs of the talented.

Two years ago the Education Committee of the Royal Society issued a discussion paper entitled "Science and the Organization of Schools in England; Implications for the Needs of Talented Children'. Here it was taken for granted that setting for science and mathematics was in the interests of talented children, that they needed to be with children of like ability and to make progress at their own rate. The fear was expressed that in small comprehensive schools, particularly if falling rolls should make them still smaller, there would not be enough children to form an O-level class. It also defended the retention of three O-levels together with a choice of subject, among other reasons because teachers can teach best what they know thoroughly. It is true that almost any reform is bad if it does not increase the teacher's confidence in his mastery of his subject; for this reason Ingle and Jennings rightly stress the need for in-service training, preferably school based.
If school education goes the way recommended by Ingle and Jennings, we can envisage a future as follows. All children will spend one-sixth of their time on science up to the age of 16 . There will be a common examination system, unifying $\mathrm{CSE}$ and O-level, but separate questions or even papers of appropriate difficulty may be set. The separate teaching of physics and the other subjects may disappear, except perhaps in the independent sector. There will be a common core; the lower ability groups will not have vague talk about science fobbed off on them but will be exposed to some real science. Ideas on the teaching of the less talented will develop, and some success is expected. Setting, however, is likely to remain. The experience with SCISP shows that talented children who have done the equivalent of two O-levels do not have difficulty with A-levels as they now are. Whether more science teachers able and willing to teach all three sciences will be found, only the future will show.

We have here a way forward which, I believe, may well be in the interests of the average child and also of the more talented child who does not want to specialize in science. But for future scientists, I have doubts. Probably a wider education, cutting down in the time spent on science up to the age of 16 , will not do them any harm. On the other hand, if they are held back, and not allowed to progress as fast as they can, they may become disillusioned and even give up the subject. How much do we want to keep the most talented back, in the interests of the majority, or of general education or for any other reason?

If the authors of this book do not see this as a major problem, they have much of interest to say on many other matters. One is the need for collaboration between the teachers of science and of mathematics; another, perhaps more original, is the help that historians ought to give in teaching the history of science. Another is the value of education in science towards learning to express oneself clearly. Finally, the authors quote Richard Peters as writing (in 1972) that "our state of ignorance with regard to teaching is comparable to that of the Greeks with regard to medicine or meteorology'. Ingle and Jennings end their book by expressing the hope that systematic school-based research will hasten the day when science teaching, while remaining an art, will become more of a science. And as a consequence, they hope, as we all must, "that the promotion of teachers might then begin to depend less on confidential references and more on soundly based competencies'.

Sir Nevill Mott was Cavendish Professor of Physics until his retirement. He was a member of the Crowther Committee on education from 16 to 18 , and has chaired various advisory committees for the Ministry of Education and for the Nuffield School Science Project. He is now a member of the Royal Society's Education Committee. 